\title{
Breeding biology, nest site characteristics and nest spacing of the Visayan Tarictic Hornbill Penelopides panini panini on Panay, Philippines
}

\author{
ERIK KLOP, EBERHARD CURIO and LUCIA L. LASTIMOZA
}

\begin{abstract}
Summary
Monitoring of nests of the Visayan Tarictic Hornbill Penelopides panini panini on the Philippine island of Panay revealed thus far undescribed information on the breeding biology of this species. Females occupied nest holes in March-April, after which two or three eggs are laid. Although cooperative breeding is suspected for the genus, at two nests no helpers were recorded. Nest-concealment behaviour was observed in the adult male. After a nestling period of 55-58 days, the adult female and one juvenile left the nest simultaneously. Immature birds resemble their respective sex. Nest site characteristics of 24 nests of the Tarictic Hornbill and two of the Writhed-billed Hornbill Aceros waldeni, respectively, were recorded on Mt Balabag, Panay Mountain Range. Tarictic Hornbill nests were situated in living as well as dead trees, at an average height of $11 \mathrm{~m}$. Cavity compass direction was uniformly distributed around the circle. Nests are aggregated within the habitat, with a mean nearest-neighbour distance of $190 \mathrm{~m}$. Writhed-billed Hornbills may require larger trees for nesting than Tarictic Hornbills. Nest density was calculated to be around three Tarictic Hornbill nests and 0.2-0.3 Writhed-billed Hornbill nests per square kilometre. Given a total amount of suitable hornbill habitat on Panay of 225-450 km², about 750-1,000 Tarictic Hornbill breeding pairs and 60-100 Writhed-billed Hornbill breeding pairs may remain on Panay.
\end{abstract}

\section{Introduction}

Hornbills are well known for their peculiar breeding habits. Apart from the two species of ground hornbills Bucorvus spp., the females of all hornbill species seal themselves into the nest hole, a characteristic for which the family is unique among birds. Natural cavities are used by most species, although some smaller species may use old barbet or woodpecker holes (Kemp 1995). Once a suitable hole is selected, the entrance is plastered with sticky materials such as mud, faeces, wood shavings and saliva, until no more than a narrow slit is left open. As a consequence, the adult female and the nestlings are dependent on the male for food provisioning.

Previous studies on the breeding ecology of Asian hornbills (e.g. Poonswad et al. 1987, Poonswad 1995, Mudappa and Kannan 1997) showed considerable differences among hornbill species in nest spacing, status of nest trees (living or dead), and nest hole characteristics (e.g. cavity dimensions and orientation). Spa- 


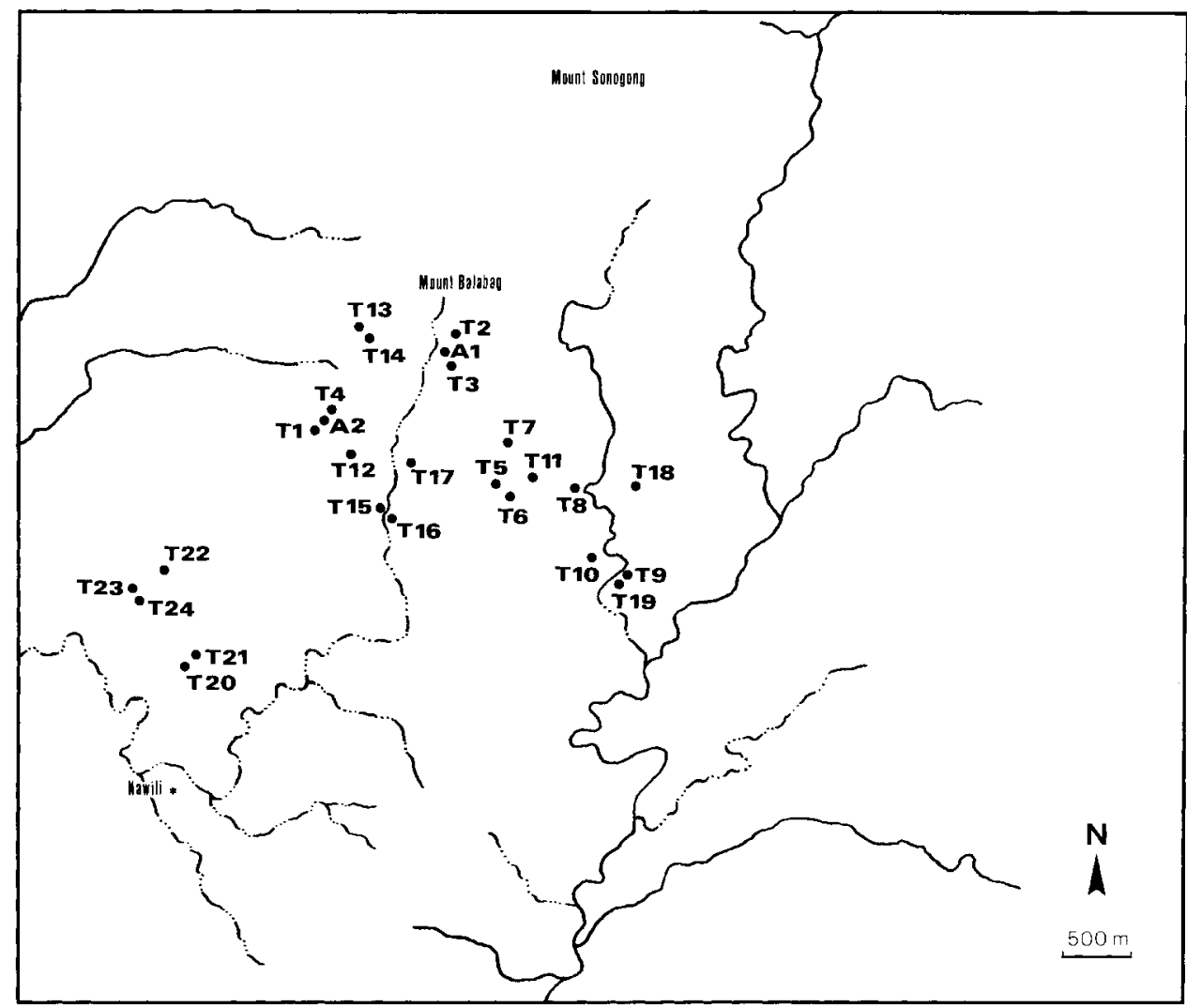

Figure 1. Location of 24 Tarictic Hornbill nest holes and two Writhed-billed Hornbill nest holes (A1, A2) on Mt Balabag (map scale 1:50,000).

cing of nests can be seen as an indicator of territorial behaviour in bird populations (e.g. Dare and Barry 1989). In a number of animals, birds included, there is regular dispersion so that between-territory distances are greater than expected by random settling (Davies 1978). Despite such spacing, however, there may be some sort of clumping. The degree of nest dispersion is usually quantified by analysis of nearest-neighbour distances between occupied nests (Ripley 1985, Dare and Barry 1989) or the number of nests present in sample plots (applied to hornbill nests by Poonswad et al. 1987).

The Visayan Tarictic Hornbill Penelopides panini panini and the Writhed-billed Hornbill Aceros waldeni are endemic to the West Visayan islands in the Philippines, and are both listed as critically endangered (Collar et al. 1994). The former species comprises an even more endangered subspecies (P. p. ticaensis) of Ticao Island that may already be extinct (Curio 1994). The breeding biology of both the Visayan Tarictic Hornbill and the Writhed-billed Hornbill has been sparsely documented, although recently some more information has become available (e.g. Kauth et al. 1998). This paper presents information on (1) the breeding biology, such as the nesting period and clutch size, (2) general characteristics of nest sites, including nest height, tree status, tree diameter, cavity orientation and dimensions, and (3) the density and spatial distribution of nests of the Visayan 
Tarictic Hornbill. Based on the density assessment, an estimation of the population of both species on the island of Panay is given. The work was undertaken as part of the Philippine Endemic Species Conservation Project (PESCP).

\section{Study area and methods}

A nest hole in the forest of Sibaliw area $\left(11^{\circ} 49^{\prime} \mathrm{N} 121^{\circ} 5^{\prime} \mathrm{E}\right)$ was observed by E.K. for 31 days between 23 April and 29 June 1997. Sibaliw is a virgin low-elevation forest located at $450 \mathrm{~m}$ in the mountain range of the north-west Panay peninsula. The nest hole was situated $9.3 \mathrm{~m}$ high in a "lamon" tree near the forest edge. The nest was monitored on alternate days, although some gaps in the schedule occurred because of typhoons. In total 369.08 hours were covered. Observations started before sunrise (about 05h15) and ended at sunset (about 18h15), so that the first and the last feeding were not missed. Walking between the camp site and the blind was done in the dark to avoid disturbance of the Tarictic Hornbills. Observations were made from a blind located 50-60 $\mathrm{m}$ from the nest tree, using a Leitz Televid 20-60 $\times 77$ spotting scope.

In July and August 1997, 24 Tarictic Hornbill nest holes and two Writhed-billed Hornbill nest holes were located on Mt Balabag, Panay Mountain Range. These nest holes were first found by Filipino scouts in 1995 and 1996 and confirmed to be occupied then by members of the PESCP. Mt Balabag lies in the BugasongValderama area, south-west of Mt Baloy (1,729 m). Mapped nest holes were located on the southern slopes of this mountain, between the village of Nawili $\left(11^{\circ} 06^{\prime} \mathrm{N} 122^{\circ} 10^{\prime} \mathrm{E}\right.$, around $\left.150 \mathrm{~m}\right)$ and Hamtang Forest $\left(11^{\circ} \mathrm{O} 8^{\prime} \mathrm{N} 122^{\circ} 11^{\prime} \mathrm{E}\right.$, around $950 \mathrm{~m}$ ). The vegetation of the area is characterized by large fields of non-native cogon grass Imperata cylindrica on the lower slopes, interspersed with fragmented forest patches which become larger towards higher elevations. The vegetation in Hamtang is primary mid-montane rainforest.

The positions of the nests were determined via the Global Positioning System (GPS) with a Garmin GPS-75 device. Acquiring satellite information for calculating the coordinates of the nest trees proved to be difficult or impossible in closedcanopy forest; therefore most GPS-bearings were taken in open spots in the forest or at the forest edge. From this position, the distance to the nest tree was estimated and the compass direction to the tree was taken in order to get the location of the nest tree relative to the GPS bearing. Nearest-neighbour distances (NNDs) were obtained by measuring from a map the distances between nest locations. Distances were rounded to the nearest $5 \mathrm{~m}$. The Clark and Evans (1954) ratio of observed and expected NNDs was calculated to assess the spatial distribution pattern. The expected NND $(r E)$ represents the expected distance between a randomly chosen individual unit and its nearest neighbour in a random dispersion pattern and is calculated by $r E=1 /\left(2 N_{1} / 2\right)$ where $N$ is the density of the population (Clark and Evans 1954). The observed NND is calculated as the mean NND $(r A)$ of $n$ observations. The measure of dispersion is calculated by $R=r A / r E$ where a value of $R=1$.o represents randomness, $R>1$.o regularity and $R<1$.o aggregation (Clark and Evans 1954). No corrections were made for edge effects.

The forest cover in Mt Balabag area was calculated with an Ushikata X-plan 36oi planimeter from the blueprint of the proposed Panay Mountains National Park made by the Land Evaluation Party (LEP) of the Department of Environ- 
ment and Natural Resources (DENR) Region VI, Iloilo City. This blueprint is based on satellite images which were not yet ground-truthed; hence the forest boundaries are not entirely correct. In order to exclude the forest patches in which no nests were searched for, or in which the nests could not be reached during the mapping, some artificial boundaries have been put on the map (mostly at rivers). The altitudinal profile of the area and thus the deviation with respect to flat land has not been taken into consideration.

For determination of the tree species, native guides were asked for the local names. Height of the nest holes was measured with a clinometer, or when possible, directly with a stick or measuring tape. A compass was used to determine the entrance orientation. The mean angle of entrance orientation was calculated following the method presented by Zar (1996). Nest cavity orientation was tested for uniformity around the circle by employing Watson's $U^{2}$ test (Zar 1996).

\section{Results}

\section{Breeding biology}

The onset of the breeding season of the Visayan Tarictic Hornbill was reported to be around April (Dickinson et al. 1991). However, sealing of the nests in the study areas occurred between 29 March and 3 April 1996 in Hamtang, on 5-6 April 1997 in Lahang (2 km east of Sibaliw), and started on 10 March 1998 in Sibaliw (J. Reiter, verbally 1998). The clutch size is two (Kemp 1995) or three. In 1995 three juveniles were robbed from a nest in Hamtang by hunters (Lastimoza and Doll unpubl. 1995). The 1997 nest in Sibaliw fledged two nestlings, but a second nest hole in the same area contained three siblings of which the smallest was found dead below the nest tree (E.K., pers. obs.). The length of the incubation period is unknown, but for the Luzon Tarictic Hornbill Penelopides manillae 2831 days is given by Kemp (1995). For the South Sulawesi Tarictic Hornbill $P$. exarhatus sanfordi, the incubation period in an incubator was 28-30 days (Mace and Azua 1997). For the North Sulawesi Tarictic Hornbill P. e. exarhatus, O'Brien (1997) estimated an incubation period of only 16-19 days in the wild, which seems to be extraordinarily short. Both the Luzon Tarictic Hornbill and the Sulawesi Tarictic Hornbill are smaller than the Visayan Tarictic Hornbill, suggesting a somewhat longer incubation period for the latter, possibly 30-35 days.

Deduced from a sudden increase both in feeding frequency and in the amount of animal food in the diet (see Klop et al. in press), the first egg in Sibaliw presumably hatched on 30 April 1997. The date of laying the second egg is unknown and could not be inferred from the feeding frequency or amount of animal food. Given the fact that small hornbills lay their eggs on consecutive or alternate days (Kemp 1995), the latter being the case, for example in a captive South Sulawesi Tarictic Hornbill (Mace and Azua 1997), the second egg possibly hatched around 2 May. Although cooperative breeding is suspected for the entire genus Penelopides (Kemp 1995), and has been confirmed for the North Sulawesi Tarictic Hornbill (O'Brien and Kinnaird 1994, O'Brien 1997), no helpers were recorded at the nest hole.

The adult female broke free and a male juvenile fledged on 24 June; the 
remaining (female) nestling followed on 29 June at $06 \mathrm{~h} 23$. This means that the nestling period of the Visayan Tarictic Hornbill is 55 to 58 days. For the Luzon Tarictic, Kemp (1995) gives 50-65 days, whereas Reinhard and Strehlow (1998) report nestling periods of 57-63 days based on data from zoos. A period of 5568 days for the North Sulawesi Hornbill is reported by O'Brien (1997).

On 27 June, the first observation day after the first nestling fledged, the male Tarictic Hornbill visited the nest hole four times without offering any food. In three visits on 25, 27 and 29 June the male offered food, but the nestling did not take it. The fledging of the second nestling on 29 June may have been induced by withholding food during visits at the nest, a behaviour which has also been observed for the Writhed-billed Hornbill by Kauth et al. (1998). Three minutes after the fledging of the second nestling, the adult female flew to the nest hole and looked inside for a few minutes.

Juvenile individuals of the Visayan Tarictic Hornbill resemble the plumage of their respective sex (E.K., pers. obs., Diesmos and Pedregosa unpubl. 1995), assuming no reversal in sexual dichromatism later on. During the nestling period the bill colour of the juveniles changes from completely horn-coloured to greyishblack. At fledging, the casque is underdeveloped and only the tip of the bill is still whitish. The characteristic of sexual dichromatism in juveniles is shared with the Luzon and Polillo Tarictic Hornbills Penelopides m. manillae and P. m. subnigra (Kemp 1995, Gonzales and Dans unpubl. 1996). In the Mindanao Tarictic Hornbill P. affinis, juveniles of both sexes resemble the plumage of the adult male (Kemp 1995), whereas in the Mindoro Tarictic Hornbill P. mindorensis, adults of both sexes are monomorphic in plumage (Kemp 1995, Diesmos and Pedregosa unpubl. 1995).

\section{Vocalizations}

The Visayan Tarictic Hornbill has a nasal contact call which sounds like $t^{\prime}$ rik ... $t^{\prime}$ rik ... $t^{\prime}$ rik-tik-tik-tik. When disturbed, a fast and repetitive series of trumpeting sounds is uttered. Nestlings emit a high-pitched begging call yeh-yeh-yeh-yeh (Lastimoza and Doll unpubl. 1995). Nasal single-note trumpeting calls were sometimes heard from the Sibaliw male at the end of the day, in the surrounding of the nest tree. Fledged juveniles were often heard uttering shrill calls resembling the normal t'rik-tik-tik but higher in pitch than the call of adult birds. The male Tarictic Hornbill did not react vocally to human disturbance close to the nest tree, but instead used to keep quiet and skulkily hop between the branches, indicating nest-concealment behaviour. On the contrary, disturbance away from the nest tree caused the birds to give loud alarm calls and fly nervously around. The wingbeat could be heard only rarely, for example when the male flew to the nest hole (E.K., pers. obs., Hahn unpubl. 1996). Similar behaviour has been observed for a male Writhed-billed Hornbill (Prim unpubl. 1998), flying silently in the vicinity of the nest, whilst otherwise a conspicuous swishing wing noise can be heard. Concealment behaviour of Tarictic Hornbills has also been observed in the presence of the Writhed-billed Hornbill when visiting the same fruit tree. The hostility between the two species is dynamic and dominance depends on the numbers of each party in a given situation (see Kauth et al. 1998). 
Nest site characteristics and nest spacing

Table 1 shows the various characteristics of 24 nest holes of the Tarictic Hornbill and two of the Writhed-billed Hornbill, respectively. In Table 2 the cavity dimensions of three Tarictic Hornbill nests are presented. The following data refer to the Tarictic Hornbill. Ten different tree species were recorded, of which two are known by scientific names (Shorea polysperma, Bischhofia javanica). Both living and dead trees were used. Mean diameter at breast height was $34 \mathrm{~cm}(n=21, \mathrm{SD}=10.1)$. Nest holes were situated at an average height of $11 \mathrm{~m}$ above ground $(n=22, \mathrm{SD}=$ 4.2), the lowest at only $1.93 \mathrm{~m}$ and the highest at $19.5 \mathrm{~m}$ above ground. The mean angle of the cavity orientation of the nests was $280^{\circ}$. Orientation of cavity entrances proved to be uniformly distributed around the circle (Watson's $U^{2}$ test, $U^{2}(0.05,21,21)=0.098, P=$ n.s. $)$. The mean observed nearest-neighbour distance between Tarictic Hornbill nests (see Figure 1 ) is $190 \mathrm{~m}(n=24, \mathrm{SD}=103.7)$. The mean expected distance if the population were distributed at random is $284 \mathrm{~m}$, with variance $2 r=22.0 \mathrm{~m}$ and standard error $R E=30.7 \mathrm{~m}$. Applying the Clark and Evans test gives a ratio $R=0.67$. Both nest holes of the Writhed-billed Hornbill were situated at a height of $17 \mathrm{~m}$ above ground.

The forest patches in which the nests were located cover a total area of about $7.76 \mathrm{~km}^{2}$, resulting in a density of about three Tarictic Hornbill nests and $0.2-0.3$ Writhed-billed Hornbill nests, respectively, per square kilometre. The forest cover of the proposed Panay Mountains National Park is as follows: old growth forest, 19,089 ha; mossy forest, 13,311 ha; residual forest, 9,956 ha; reproduction brush, 25,912 ha (source: Land Evaluation Party/Department of Environment and Natural Resources, Region VI, Iloilo City).

On the assumption that there are no suitable nest trees in reproduction brush, the total area of suitable hornbill habitat in the Panay Mountain Range may amount to approximately $425 \mathrm{~km}^{2}$ (T. Hahn unpubl. 1996). However, parts of the mossy forest might be too high in elevation and parts of the residual forest might be too heavily logged to provide suitable hornbill habitat. On the other hand, Tarictic Hornbill nests have been found in rather isolated trees with no forest around. Exclusion of residual and mossy forest results in an area of only $200 \mathrm{~km}^{2}$ in the Panay Mountain Range. The forest cover in the north-west Panay peninsula is estimated to be $25 \mathrm{~km}^{2}$ (de Soye unpubl. 1997). The total area of suitable hornbill habitat on Panay may thus range from about 225 to $450 \mathrm{~km}^{2}$. Ignoring edge effects and non-breeding individuals in the population, extrapolation of the density of Mt Balabag to the entire island then results in about 750-150o breeding pairs of the Tarictic Hornbill and 60-100 of the Writhed-billed Hornbill left on Panay.

\section{Discussion}

The selection of nest sites by hornbills may depend on characteristics of the nest cavity itself and of the surrounding habitat. The availability of suitable cavities is likely to be limited (Kemp 1995), especially in disturbed forests where large trees are being illegally logged for commercial purposes. Interspecific competition for nest sites, as illustrated by the immediate takeover of a White-bellied Woodpecker Dryocopus javensis nest hole, following fledging or nest-predation, 
Table 1. Nest site characteristics and distances to the nearest conspecific neighbour of 24 Tarictic Hornbill nests and two Writhed-billed Hornbill nests, A1 and A2

\begin{tabular}{|c|c|c|c|c|c|c|}
\hline No. & $\begin{array}{l}\text { Tree species } \\
\text { (local name) }\end{array}$ & $\begin{array}{c}\text { Diameter } \\
\text { at breast } \\
\text { height }(\mathrm{cm})\end{array}$ & $\begin{array}{c}\text { Height of } \\
\text { nest hole }(\mathrm{m})\end{array}$ & $\begin{array}{c}\text { Cavity } \\
\text { orientation }^{\mathrm{a}}\end{array}$ & $\begin{array}{c}\text { Distance to } \\
\text { nearest } \\
\text { neighbour }(\mathrm{m})\end{array}$ & Comments \\
\hline 1 & Liptog & 55 & $1.93^{\mathrm{d}}$ & - & 150 & \\
\hline 2 & - & - & 12 & 240 & 200 & Dead tree \\
\hline 3 & Balakbakan ${ }^{\text {b }}$ & - & 15 & 340 & 200 & \\
\hline 4 & - & 55 & 12 & 150 & 150 & Dead tree \\
\hline 5 & Dungon & 17 & $5 \cdot 98^{\mathrm{d}}$ & - & 115 & \\
\hline 6 & Alomangog & 37 & 20 & 190 & 115 & \\
\hline 7 & Dungon & 38 & 10 & 280 & 300 & \\
\hline 8 & Kalulot & 21 & 14 & 245 & 330 & \\
\hline 9 & Kabnol & 29 & 15 & 150 & 130 & Robbed \\
\hline 10 & Kabnol & $37^{\mathrm{e}}$ & $4 \cdot 50^{\mathrm{d}}$ & - & 330 & Fallen down \\
\hline 11 & Kabnol & 26 & $5 \cdot 30^{\mathrm{d}}$ & 90 & 215 & Robbed \\
\hline 12 & Alomangog & 34 & $10^{f}$ & 325 & 285 & \\
\hline 13 & Kalulot & 30 & 14 & 190 & 100 & \\
\hline 14 & Kabnol & 32 & - & 160 & 100 & \\
\hline 15 & Lawihaw & 26 & 11 & o & 115 & Robbed \\
\hline 16 & Lawihaw & 28 & 8 & 80 & 115 & \\
\hline 17 & $\operatorname{Toog}^{c}$ & 28 & 7 & 95 & 385 & \\
\hline 18 & Balik-buyo & 27 & 11 & 270 & 435 & \\
\hline 19 & Dungon & 43 & 12 & 340 & 130 & \\
\hline 20 & Toog & 46 & 16 & 250 & 115 & \\
\hline 21 & Alomangog & 29 & 12 & 250 & 115 & Robbed \\
\hline 22 & Dungon & 35 & 16 & 130 & 265 & Dead tree \\
\hline 23 & Salong & 45 & 14 & 185 & 85 & \\
\hline 24 & Dungon & 一 & - & 200 & 85 & \\
\hline $\mathrm{A} 1$ & Balakbakan ${ }^{b}$ & - & 17 & 150 & 1000 & Robbed \\
\hline $\mathrm{A} 2$ & Dungon & 90 & 17 & 230 & 1000 & \\
\hline
\end{tabular}

${ }^{a}$ Cavity orientation in degrees subtended from North.

${ }^{\mathrm{b}}$ Balakbakan is Shorea polysperma (Dipterocarpaceae).

${ }^{\mathrm{c}}$ Toog is Bischhofia javanica (Euphorbiaceae).

${ }^{\mathrm{d}}$ Direct measurement.

${ }^{\mathrm{e}}$ Diameter at nest height.

${ }^{\mathrm{f}}$ Estimated height.

Table 2. Cavity dimensions $(\mathrm{cm})$ of three Tarictic Hornbill nests

\begin{tabular}{lccccc}
\hline Nest hole & $\begin{array}{c}\text { Height of } \\
\text { ceiling }^{\mathrm{a}}\end{array}$ & Floor depth & Diameter & $\begin{array}{c}\text { Height of } \\
\text { entrance }\end{array}$ & $\begin{array}{c}\text { Width of } \\
\text { entrance }^{\mathrm{c}}\end{array}$ \\
\hline 1 & 111 & 7 & 36 & 25 & 10 \\
10 & 93 & 40 & 33 & -11 & - \\
11 & 110 & 31 & - & - & 8 \\
\hline
\end{tabular}

${ }^{a}$ Measured from the top of the entrance to the top of the nest cavity.

${ }^{b}$ Depth from the base of the entrance to the centre of the cavity floor.

${ }^{c}$ Without seal.

by a pair of Blue-crowned Racquet-tails Prioniturus discurus in Sibaliw Forest (J. Reiter in litt. 1998) may influence nest site selection (Mudappa and Kannan 1997). Furthermore, the presence of food sources (Kemp 1995, Mudappa and Kannan 1997), predation (Kemp 1995), microclimate inside the cavity (Poonswad 1995, 
Kemp 1995), and entrance size (Poonswad 1995) may all influence cavity choice. Nests were predominantly found in trunks of living trees, although three were situated in dead trees. Hornbills usually nest in living trees (see Kemp 1995, Poonswad 1995), since dead trees are not likely to last long and their microclimate may not be suitable when in direct sunlight (Poonswad 1995). However, nests of some species (Oriental Pied Hornbill Anthracoceros albirostris, Bushycrested Hornbill Anorrhinus galeritus, Great Rhinoceros Hornbill Buceros rhinoceros) have occasionally been found in dead trees (see Kemp 1995, Poonswad 1995). Although never confirmed, records of Tarictic Hornbill nests in a rock cliff were reported by locals (Curio et al. 1996).

No preference of a particular cavity orientation could be observed, corresponding with results on four species of Thai hornbills (Poonswad et al. 1987, Poonswad 1995). However, in examining nest characteristics of the Malabar Gray Hornbill Ocyceros griseus, Mudappa and Kannan (1997) found significantly more nest cavities that were oriented in the north-east direction. Cavity dimensions varied, but all "funk holes" of the measured cavities reached around a metre above the entrance. In two out of three cavities, the floor was lying deep below the entrance, whereas in the third cavity the floor depth was only $5-7 \mathrm{~cm}$. However, in the last the lower part of the entrance was completely closed with sealing material, giving a functional depth much greater than $5-7 \mathrm{~cm}$. Cavities with relatively high-lying floors may need a high entrance slit for sufficient ventilation, whereas in cavities with deep floors a small entrance may provide sufficient ventilation.

The Visayan Tarictic Hornbill uses natural cavities as well as old woodpecker holes for nesting. Three species of woodpecker occur on Panay, the White-bellied Woodpecker, Philippine Pygmy Woodpecker Dendrocopus maculatus and the Greater Flameback Chrysocolaptes lucidus. Cavities produced by the last two species are probably too small for the hornbills. Dryocopus javensis was only rarely recorded during fieldwork, and the Visayan subspecies D. j. philippinensis might be seriously threatened (Oliver and Wirth unpubl. 1993).

Tarictic Hornbill nests were on the average located at lower heights than Writhed-billed Hornbill nests. Although the diameter at breast height of only one Writhed-billed Hornbill nest tree was measured, it proved to be substantially more than any of the recorded Tarictic Hornbill nest trees. Writhed-billed Hornbills may thus, unsurprisingly, require much larger trees for nesting than Tarictic Hornbills.

The observed nearest-neighbour distances are shorter than would be expected by regular spacing out of territory owners. However, the Clark and Evans test pertains to a homogeneous, continuous forest, which is not the situation in the study area. If the optimal nearest-neighbour distance is longer than a patch of forest allows, clumping, i.e. settling closer together than dictated by homogeneity of habitat, would be due to a constraint. The non-randomness of spacing might therefore be dictated by the fragmentation of habitat and, hence, the clumping may not be real.

The pattern of clumping described has also been observed rarely elsewhere, for example in Pied Flycatchers Ficedula hypoleuca. Yet in spite of settling being clumped there is still regular spacing out on a finer scale (Lundberg and Alatalo 1992). This balance between repulsion and clumping may reflect a mutual antipredator strategy between neighbours. Given that clumping leaves no 
unguarded terrain between territories, chasing of predators may be particularly effective. Additionally, if the attack on a predator transcends the territory boundary there will be mutually advantageous mass attacks by neighbours and, hence, clumped settling gives benefits in yet another way (Davies 1978). This question still needs attention with regard to the Tarictic Hornbill.

In the forest cover calculation, a rather high degree of inaccuracy is likely to have occurred for several reasons. The blueprint from which the forest cover is calculated is based on satellite images which were not yet confirmed on the ground. The calculation is therefore unlikely to be entirely correct, which was confirmed by GPS bearings taken on reference points such as trails and rivers. In order to exclude forest in which nest holes were not searched for, some artificial boundaries (mostly rivers) have been put on the map. Additionally, the altitudinal profile of the area, and thus the deviation with respect to flat land, has been ignored in the calculation. In spite of the inaccuracy, an estimate of $7.5-8 \mathrm{~km}^{2}$ may give a fair approximation of the forest cover of the searched area. The total area of suitable hornbill habitat on Panay is estimated to be $225-450 \mathrm{~km}^{2}$, depending on whether mossy and residual forest are considered "suitable". Parts of the mossy forest might be too high in elevation, and parts of the residual forest might lack potential nest trees due to selective logging. However, the extent to which altitude and habitat quality affect Tarictic Hornbill populations is unknown.

Given the numerous uncertainties, calculating the nest density and population numbers accurately seems nearly impossible. In spite of this, the necessity of conservation efforts is evident from the presented data. Both Visayan hornbill species prove to be heavily hunted, be it either for subsistence or for the pet trade. As shown in Table 1, four of the 24 mapped Tarictic Hornbill nests and one of the two Writhed-billed Hornbill nests, respectively, were robbed in 1997. In 1998 no fewer than 20 Tarictic Hornbill nestlings and two Writhed-billed Hornbill nestlings found mainly at three markets (of which two are located in the north-west Panay peninsula) were confiscated or purchased from illegal pet dealers. Based on the estimate of $c .3$ Tarictic Hornbill pairs and 0.2-0.3 Writhedbilled Hornbill pairs per square kilometre the total population numbers can be assessed. Given the ongoing deforestation and severe hunting pressure, a pessimistic population estimate of perhaps 750 breeding Tarictic Hornbill pairs remaining on Panay seems to be most realistic. Population numbers on Negros are unknown, but they are certainly much smaller. The Visayan Tarictic Hornbill might thus be - at the moment - out of immediate danger from demographic, environmental or genetic stochasticity (see Gilpin and Soulé 1986, Shaffer 1987, Lande 1993), but could soon become so if the present hunting pressure and deforestation rates continue. The situation of the Writhed-billed Hornbill gives reason for very serious conservation concern. With a population number less than 75 breeding pairs on Panay, this species is literally on the brink of extinction.

\section{Acknowledgements}

We would like to thank the members of the PESCP teams in Hamtang and Sibaliw, especially N. Arsenio, M. Ballhaus, J. Berdin, T. Dalumpines, R. Ebon, B. Gonzales, N. Jarño, G. Meier, S. Peters, Y. de Soye and B. Tacud, for all their support. We also thank the people of Nawili for their overwhelming hospitality. 
Further support came from the Frankfurt Zoological Society, the Andreas-StihlStiftung, the EU, the German Ornithologists' Society, the Ministry of Science and Research of the Land North Rhine Westfalia, Prof. Dr Dr mult. h.c. Ernst Mayr, Cambridge, MA, and Mr Claus Sudhoff (Cavite). The Protected Areas and Wildife Bureau and the Land Evaluation Party (coordinator Mr Henry M. Balmores) of the DENR (Director Wilfrido S. Pollisco, Region VI RED R. Geollegue and RTD R. Pangahas) and West Visayas State University (President Dr Bernabe B. Cocjin and the dean of the College of Agriculture and Forestry Dr Eleodoro L. Alicante) provided advice and support throughout. To all these persons and organizations we are immensely grateful. This paper is publication No. 16 of the Philippine Endemic Species Conservation Project (PESCP) of the Frankfurt Zoological Society.

\section{References}

Clark, P. J. and Evans, F. C. (1954) Distance to nearest neighbour as a measure of spatial relationships in populations. Ecology 35: 445-452.

Collar, N. J., Crosby, M. J. and Stattersfield, A. J. (1994) Birds to watch 2: the world list of threatened birds. Cambridge, U.K.: BirdLife International (BirdLife Conservation Series 4).

Curio, E. (1994) Ornithological observations during a (preliminary) Philippines conservation expedition in 1993. Ecol. Birds 16: 613-623.

Curio, E., Hamann, A., Heubüschl, P. and Lastimoza, L. L. (1996) Hornbill research and conservation in the Philippines. EEP Hornbill TAG Newsletter 2: 26-27.

Dare, P. J. and Barry, J. T. (1989) Population size, density and regularity in nest spacing of Buzzards Buteo buteo in two upland regions of North Wales. Bird Study 37: 23-29.

Davies, N. B. (1978) Ecological questions about territorial behaviour. Pp. 317-350 in J. R. Krebs and N. B. Davies, eds. Behavioural ecology, an evolutionary approach. Oxford: Blackwell Scientific Publications.

Dickinson, E. C., Kennedy, R. S. \& Parkes, K. C. (1991) The birds of the Philippines, an annotated checklist. Tring: British Ornithologists' Union (Checklist 12).

Gilpin, M. E. and Soulé, M. E. (1986) Minimum viable populations: processes of species extinction. Pp. 19-34 in M. E. Soulé, ed. Conservation biology: the science of scarcity and diversity. Sunderland, MA: Sinauer Associates.

Kauth, M., Engel, S., Lastimoza, L. L. and Curio, E. (1998) Observations on the breeding biology of the Writhed-billed Hornbill (Aceros waldeni) in the Philippines. J. Ornithol. 139: $475-483$.

Kemp, A. (1995) The hornbills. Oxford: Oxford University Press.

Klop, E., Hahn, T., Kauth, M., Engel, S., Lastimoza, L. L. and Curio, E. (in press) Diet composition and food provisioning of the Visayan Tarictic Hornbill (Penelopides panini panini) during the breeding season. Ecol. Birds.

Lande, R. (1993) Risks of population extinction from demographic and environmental stochasticity and random catastrophes. Amer. Nat. 142: 911-927.

Lundberg, A. and Alatalo, R. V. (1992) The Pied Flycatcher. London: T. \& A. D. Poyser.

Mace, M. and Azua, J. (1997) Breeding and hand-rearing the Southern Sulawesi hornbill (Penelopides exarhatus sanfordi) for the Zoological Society of San Diego. Internatn. Zoo Yearbook 35: 247-253.

Mudappa, D. C. and Kannan, R. (1997) Nest-site characteristics and nesting success of the Malabar Gray Hornbill in the Southern Western Ghats, India. Wilson Bull. 109: 102-111.

O'Brien, T. G. (1997) Behavioural ecology of the North Sulawesi Tarictic Hornbill (Penelopides exarhatus exarhatus) during the breeding season. Ibis 139: 97-101. 
O'Brien, T. G. and Kinnaird, M. F. (1994) Notes on the density and distribution of the endemic Sulawesi Tarictic Hornbill (Penelopides exarhatus) in Tangkoko-Dua Suadara Nature Reserve, North Sulawesi. Trop. Biodiv. 2:252-260.

Poonswad, P. (1995) Nest site characteristics of four sympatric species of hornbills in Khao Yai National Park, Thailand. Ibis 137: 183-191.

Poonswad, P., Tsuji, A. and Ngampongsai, C. (1987) A comparative study on breeding biology of sympatric hornbill species (Bucerotidae) in Thailand with implications for breeding in captivity. In Proceedings of the J. Delacour/IFCB Symposium, Los Angeles, CA.

Reinhard, R. and Strehlow, H. (1998) Die Haltung und Zucht von Nashornvögeln (Bucerotidae) im Zoologischen Garten Berlin. Zool. Garten 68: 1-16.

Ripley, B. D. (1985) Analyses of nest spacings. Pp. 151-158 in P. M. North, and B. J. T. Morgan, eds. Statistics in ornithology. Berlin: Springer.

Shaffer, M. (1987) Minimum viable populations: coping with uncertainty. Pp. 69-86 in M. E. Soulé, ed. Viable populations for conservation. Cambridge, U.K.: Cambridge University Press.

Zar, J. H. (1996) Biostatistical analysis. Third edition. Upper Saddle River: Prentice-Hall.

\section{ERIK KLOP}

Oostercluft 149, 8332 DC Steenwijk, The Netherlands

EBERHARD CURIO

D-44780 Bochum, Germany Conservation Biology Unit, Faculty of Biology, Ruhr-Universität Bocum,

LUCIA L. LASTIMOZA

West Visayas State University, Supply Office, Iloilo City, Philippines 